\title{
D-serine and NMDA Receptor 1 Expression in Patients with Intractable Epilepsy
}

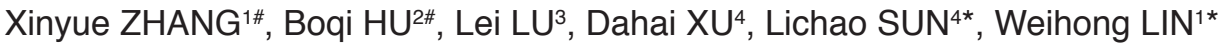 \\ ${ }^{1}$ The First Hospital of Jilin University, Department of Neurology, Changchun, Jilin, China \\ ${ }^{2}$ China-Japan Union Hospital of Jilin University, Department of Radiology, Changchun, Jilin, China \\ ${ }^{3}$ Harrison International Peace Hospital, Department of Neurology, Hengshui, Hebei, China \\ ${ }^{4}$ The First Hospital of Jilin University, Department of Emergency Medicine, Changchun, Jilin, China \\ "Xinyue ZHANG and Boqi HU contributed equally to this work and are co-first authors. \\ *Lichao SUN and Weihong LIN contributed equally and are co-corresponding authors.
}

Corresponding author: Lichao SUN, Weihong LIN sunlichao5@sina.com, linweihong321@126.com

\section{ABSTRACT}

AIM: To investigate the expression patterns of D-serine and N-methyl-D-aspartate (NMDA) receptor 1 in the temporal lobes of patients with intractable epilepsy.

MATERIAL and METHODS: Cortical temporal lobe brain tissue samples were collected from 20 patients with intractable epilepsy and 6 patients with brain trauma. The expression patterns of D-serine and NMDA receptor 1 were detected by immunofluorescence staining and western blot analysis.

RESULTS: A total of 20 patients (11 males, 9 females) were included in the present study. D-serine expression was significantly higher in the neurons and glial cells of patients with intractable epilepsy than in control individuals. The mean integrated optical density $(I O D)$ value for the intractable epilepsy group $(13.37 \pm 1.88)$ was significantly higher than that for the control group $(9.27 \pm$ $0.62, p<0.05)$. The mean absorbance value of the NMDA receptor 1 protein strip obtained from intractable epileptic patients was $0.4175 \pm 0.2321$, which was significantly higher than the value of $0.2402 \pm 0.1458$ for the control group $(p<0.05)$.

CONCLUSION: D-serine and NMDA receptor 1 expressions increased significantly in patients with intractable epilepsy compared with control patients. Therefore, the D-serine signaling pathway may represent a potential neurochemical target for epilepsy treatment.

KEYWORDS: Intractable epilepsy, Temporal lobe, NMDA, D-serine

ABBREVIATIONS: NMDA: N-methyl-D-aspartate, EEG: Electroencephalogram, IOD: Integrated optical density, CT: Computed tomography, MRI: Magnetic resonance imaging, RT: Room temperature, PBS: Phosphate-buffered saline; FITC: Fluorescein isothiocyanate, GFAP: Glial fibrillary acidic protein, TRITC: Tetramethylrhodamine, SDS-PAGE: Sodium dodecyl sulfatepolyacrylamide gel electrophoresis, PVDF: Polyvinylidene difluoride, FLAIR: Fluid-attenuated inversion recovery, SR: Serine racemase

Xinyue ZHANG (1) : 0000-0002-6434-5599

Boqi HU : 0000-0003-4679-9690

Lei LU (10) : 0000-0002-7044-8404
Dahai XU (10): 0000-0002-9029-2523

Lichao SUN (1D): 0000-0003-2452-045X

Weihong LIN (1) : 0000-0002-7738-3949 


\section{- INTRODUCTION}

$\mathrm{E}$ pilepsy is a common neurological disorder; it is characterized by abnormal, synchronous electrical activity in the brain that results in recurrent, unprovoked seizures. About $30 \%$ of patients with epilepsy do not respond to antiepileptic drugs (3) and are diagnosed with intractable epilepsy, which is associated with poor functional outcomes. Because the exact cause and pathogenesis of intractable epilepsy remain unclear, understanding of the underlying mechanisms associated with intractable epilepsy has become a popular research topic in recent years. Temporal lobe epilepsy accounts for more than $50 \%$ of the cases of intractable epilepsy and is also associated with poor outcomes. Therefore, understanding the pathogenesis of temporal lobe epilepsy is of critical importance for the development of potential treatment options.

$\mathrm{N}$-methyl-D-aspartate (NMDA) is an amino acid derivative that acts as a specific agonist of the NMDA glutamate receptor, where it mimics the action of glutamate. The NMDA glutamate neurotransmitter receptor has been extensively researched and plays a significant role in the development of epilepsy. Previous reports have described the upregulation of NMDA receptors in the brain tissues of patients with epilepsy, and NMDA receptor upregulation has been shown to be associated with the development of epilepsy $(10,17,27)$. Whole-cell patch-clamp and single-channel recording studies have found that the NMDA channel has an increased mean open time and excitatory postsynaptic discharge, which may potentially increase the susceptibility of epilepsy (28). Investigators found that an NMDA receptor antagonist may regulate the occurrence of seizure and prevent secondary brain structure changes in animal models that mimic human temporal lobe epilepsy $(25,26)$. However, NMDA receptor blockades may cause severe adverse reactions. Therefore, a thorough understanding of the neurochemical pathways involved in epilepsy may facilitate the identification of potential therapeutic targets and the development of new antiepileptic drugs. Studies examining $\mathrm{H}^{3}$-labeled D-serine have suggested that D-serine may selectively bind to the glycine site of NMDA-type glutamate receptors (15). The D-serine distribution closely parallels the NMDA receptor distribution in the brain, suggesting that they may be functionally correlated. Diseases associated with NMDA receptor dysfunction may also be associated with D-serine changes. Therefore, an understanding of the interactions between D-serine and NMDA receptors may facilitate the exploration of NMDA receptor dysfunctions associated with neurological disease pathogenesis and may provide a new therapeutic approach for epilepsy.

Our study aimed to investigate the expression patterns of D-serine and NMDA receptor 1 in the temporal lobe using immunofluorescence staining and western blot analysis of the brain tissue samples obtained from 20 patients with intractable epilepsy (Table I).

\section{MATERIAL and METHODS}

\section{Subjects}

Institutional review board approval and informed consent from all patients were obtained before beginning the present study. Cortical temporal lobe brain tissues were collected from patients with intractable epilepsy, who were treated at the epilepsy surgery center at the First Hospital of Jilin University. The inclusion criteria of the present study were as follows: 1) patients with clinical signs, symptoms, and electroencephalogram (EEG) features suggestive of epilepsy; 2) patients treated with two or more antiepileptic drugs for at least 2 years, without relief from seizure episode; 3) patients who fit into one of the epilepsy types proposed by the 1989 International League Against Epilepsy (ILAE) classification of epilepsies; and 4) patients whose brain computer tomography (CT) or magnetic resonance imaging (MRI) scans did not reveal any lesions of the central nervous system, except for hippocampal sclerosis. Cortical brain tissues were collected from patients with brain traumas, who were treated at the Department of Neurosurgery at the First Hospital of Jilin University and China-Japan Friendship Hospital and were used as controls. A total of six patients (four males, two females) were included as control patients, with no history of epilepsy or any other hereditary diseases. The average age of the control patients was $36.83 \pm 16.31$ years (age range: 19-55 years). Pathological examinations were normal in all control patients (Table II).

\section{Sample Preparation}

For immunofluorescence staining and western blot analysis, a portion of the resected brain tissue from each subject (both the epilepsy group and the control group) was immediately washed three times with normal saline and soaked in liquid nitrogen for $10-20 \mathrm{~s}$. The samples were then stored at $-80^{\circ} \mathrm{C}$ until analysis.

\section{D-serine Immunohistochemistry}

Brain tissues were sectioned, at a $5-\mu \mathrm{m}$ thickness, and stored at room temperature (RT) for $30 \mathrm{~min}$. The samples were fixed in $-20^{\circ} \mathrm{C}$ acetone for $10 \mathrm{~min}$, rinsed twice in phosphatebuffered saline (PBS) for 5 min each wash, and then incubated with $10 \%$ goat serum for $30 \mathrm{~min}$. The serum was removed, and the samples were incubated with a rabbit $D$-serine polyclonal antibody (1:12,500 dilution) at $4^{\circ} \mathrm{C}$ overnight. The next day, the samples were washed three times with PBS, for $5 \mathrm{~min}$ each wash, and then incubated with fluorescein isothiocyanate (FITC)-conjugated goat anti-rabbit IgG for 60 min. After washing the samples three times with PBS, the brain sections were examined, and images of interest were captured using a confocal laser scanning microscope (CLSM, FV1000, Olympus). Ten high-power fields of view were chosen for each brain section, and the expression level of D-serine was determined using the Image-Pro Plus 6.0 software (Media Cybernetics, USA).

\section{Double Labeling for D-serine/NeuN and D-serine/GFAP}

Brain tissues were sectioned at a 5- $\mu \mathrm{m}$ thickness and stored at RT for $30 \mathrm{~min}$. The samples were fixed in $-20^{\circ} \mathrm{C}$ acetone 
for $10 \mathrm{~min}$; rinsed twice in PBS, for 5 min each wash; and then incubated with $10 \%$ goat serum for $30 \mathrm{~min}$. The serum was then removed, and the samples were incubated with a rabbit anti-D-serine polyclonal antibody (1:12,500 dilution) and a mouse anti-human glial fibrillary acidic protein (GFAP) $\operatorname{lgG}$ at $4^{\circ} \mathrm{C}$ overnight. The samples were washed three times with PBS, for 5 min each wash, and then incubated with FITCconjugated goat anti-rabbit IgG and tetramethylrhodamine (TRITC)-conjugated goat anti-mouse IgG for $60 \mathrm{~min}$. After washing the samples three times with PBS, the brain sections were examined, and images of interest were captured using a laser scanning confocal microscope (LSCM, FV1000, Olympus).

\section{Western Blot Analysis}

Western blot analysis was conducted to compare the D-serine levels between patients with temporal lobe epilepsy and control patients who suffered from brain trauma. The brain samples were cut into small pieces and homogenized. Protein was extracted from the samples and stored at $-20^{\circ} \mathrm{C}$ for future use. The extracts were then resolved by sodium dodecyl sulfate-polyacrylamide gel electrophoresis (SDS-PAGE), and the proteins were electrotransferred to a polyvinylidene difluoride (PVDF) membrane (Dupont). After extensive washing with PBS, the membranes were incubated with a rat anti-NMDA receptor $1 \mathrm{lgG}(1: 100)$ at $4^{\circ} \mathrm{C}$ overnight, and an alkaline phosphatase-conjugated goat anti-rabbit antibody was added at a 1:1,000 dilution and incubated for $1 \mathrm{~h}$. After washing with PBS, the immunoreactive bands were visualized using SimplySensitive AP-NBT/BCIP In Situ Detection System. In our study, PBS was used as a negative control and $\beta$-actin as a positive control. The band intensity ratios from the same electrophoresis run were analyzed.

\section{Statistical Analysis}

All statistical analyses were conducted using SPSS 17.0 (IBM, USA). All values were expressed as mean \pm standard deviation. Statistical significance was assessed using Student's $t$-test, and a $p$-value $<0.05$ was considered significant.

Table I: Clinical Profiles of the 20 Patients with Intractable Epilepsy

\begin{tabular}{|c|c|c|c|c|c|c|c|}
\hline Age $(Y)$ & Sex & $\begin{array}{c}\text { Disease } \\
\text { duration }(Y)\end{array}$ & $\begin{array}{c}\text { Epilepsy } \\
\text { Type }\end{array}$ & Location & Pathology & Head MRI & EEG \\
\hline 18 & $\mathrm{~F}$ & 2 & CPS & TL R & $\mathrm{ND}, \mathrm{G}$ & normal & abnormal \\
\hline 22 & $M$ & 4 & GTCS, CPS & TL R & ND & abnormal & abnormal \\
\hline 58 & $\mathrm{~F}$ & 15 & SPS, CPS & TL L & $\mathrm{ND}, \mathrm{NL}, \mathrm{G}$ & normal & abnormal \\
\hline 40 & $\mathrm{~F}$ & 3 & CPS & TL R & $N D, G$ & abnormal & abnormal \\
\hline 22 & M & 5 & GTCS & TL L & G & abnormal & abnormal \\
\hline 49 & M & 29 & CPS & TL L & $N L, G$ & abnormal & abnormal \\
\hline 23 & $\mathrm{M}$ & 2 & CPS, GTCS & TL L & ND, G & abnormal & abnormal \\
\hline 20 & $M$ & 7 & GTCS & TL R & $\mathrm{ND}, \mathrm{G}$ & abnormal & abnormal \\
\hline 19 & $\mathrm{M}$ & 5 & GTCS, SPS & TL L & G & abnormal & abnormal \\
\hline 22 & $\mathrm{~F}$ & 20 & CPS & TL R & ND & abnormal & abnormal \\
\hline 21 & $\mathrm{~F}$ & 10 & SPS, CPS & TL R & G, NL & abnormal & abnormal \\
\hline 20 & $\mathrm{~F}$ & 16 & SPS & TL L & $\mathrm{NL}, \mathrm{ND}, \mathrm{G}$ & abnormal & abnormal \\
\hline 27 & $\mathrm{~F}$ & 9 & CPS, GTCS & TL R & G & normal & abnormal \\
\hline 27 & $M$ & 16 & CPS & TL L & $\mathrm{G}$ & abnormal & abnormal \\
\hline 35 & $\mathrm{~F}$ & 3 & CPS & TL R & ND, G & abnormal & abnormal \\
\hline 17 & $M$ & 5 & GTCS & TL L & $\mathrm{ND}, \mathrm{G}$ & normal & abnormal \\
\hline 17 & $\mathrm{~F}$ & 6 & GTCS, CPS & TL R & $\mathrm{NL}, \mathrm{G}$ & abnormal & abnormal \\
\hline 33 & $M$ & 4 & CPS & TL L & ND & abnormal & abnormal \\
\hline 28 & $M$ & 6 & GTCS & TL R & ND, G & abnormal & abnormal \\
\hline 36 & M & 22 & CPS & TL R & G & abnormal & abnormal \\
\hline
\end{tabular}

M: Male, F: Female, CPS: Complex partial seizure, GTCS: Generalized tonic-clonic seizure, SPS: Simple partial seizure, TL: Temporal lobe, L: left, R: Right, ND: Neurons generation, NL: Neurons loss, G: Gliosis.

Table II: Clinical Profiles for the Six Control Patients

\begin{tabular}{ccccc}
\hline Age $(\mathbf{Y})$ & Sex & Diagnosis & Location & Pathology \\
\hline 55 & M & Trauma & TL L & normal \\
28 & F & Trauma & TL R & normal \\
19 & M & Trauma & TL L & normal \\
49 & F & Trauma & TL R & normal \\
20 & M & Trauma & TL L & normal \\
50 & M & Trauma &
\end{tabular}

M: Male, F: Female, TL: Temporal lobe, L: Left, R: Right. 


\section{RESULTS}

A total of 20 patients (11 males, 9 females) with intractable epilepsy were included in our study. The average age of the patients was $27.7 \pm 11.13$ years (age range: $17-58$ years), and the average disease duration was $9.45 \pm 7.65$ years (range: $2-29$ years). The disease duration was $>5$ years in $14(70 \%)$ patients and $>10$ years in $7(35 \%)$ patients. The types of seizures observed in our patient population included complex partial seizures, generalized tonic-clonic seizures, and simple partial seizures. Neuropathological examination revealed neuronal degeneration, glial proliferation, and neuronal loss in patients with intractable epilepsy. An MRI was also performed in all 20 patients with intractable epilepsy. The results revealed that 4 patients had normal scans, whereas the other 16 patients had abnormal MRI findings, including hippocampal atrophy, medial temporal lobe hyperintensity on T2, fluid-attenuated inversion recovery (FLAIR) images, and an enlarged temporal horn of the lateral ventricle. EEG activity was abnormal in all 20 patients (Table I).

\section{Distribution of D-serine in Patients with Intractable Epilepsy}

Confocal laser scanning microscopy revealed D-serine expression in the neurons and glial cells of both patients with intractable epilepsy and control patients (Figures 1A, B and 2A, $B)$. D-serine expression was significantly increased in patients with intractable epilepsy compared with control patients, and we found that the integrated optical density (IOD) value for the intractable epilepsy group (13.37 \pm 1.88$)$ was significantly higher than that for the control group $(9.27 \pm 0.62, p<0.05$, Figure 3A, B).

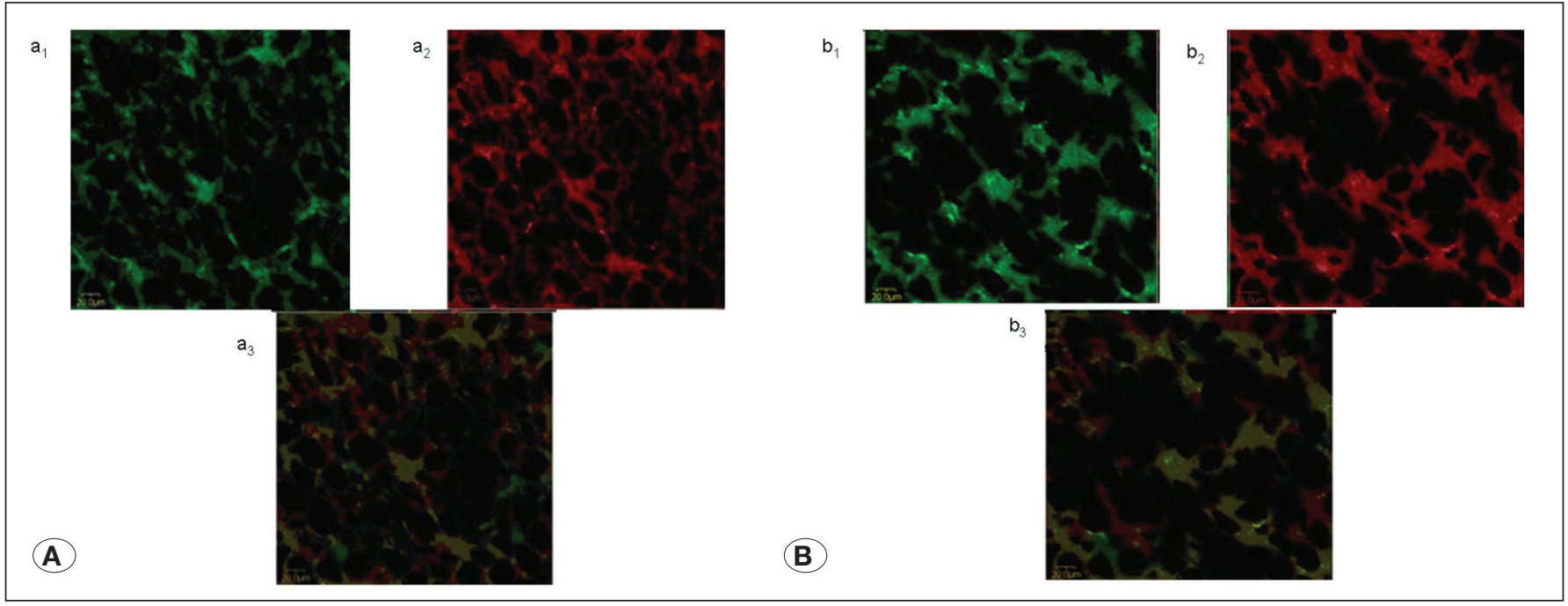

Figure 1: Double immunofluorescence staining, showing the co-expression of D-serine and GFAP in (A) the control group and (B) the intractable epilepsy group. D-serine appears as green fluorescence (a1 and b1), whereas GFAP appears as red fluorescence (a2 and b2). Areas with both proteins in the superimposed pictures (a3 and b3) appear yellow.
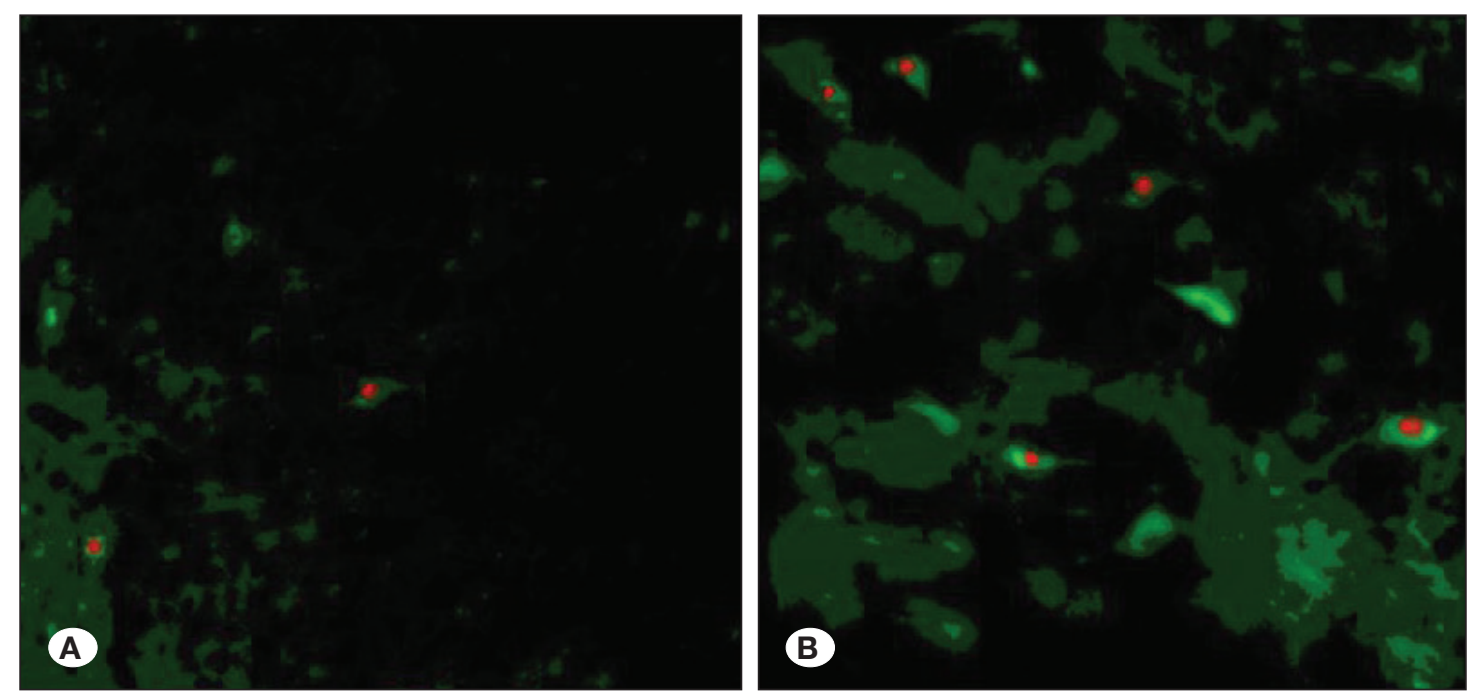

Figure 2: Double immunofluorescence staining revealed the co-expression of D-serine and NeuN in (A) the control group and $(\mathbf{B})$ the intractable epilepsy group.

D-serine appears as green fluorescence and NeuN as red fluorescence. 

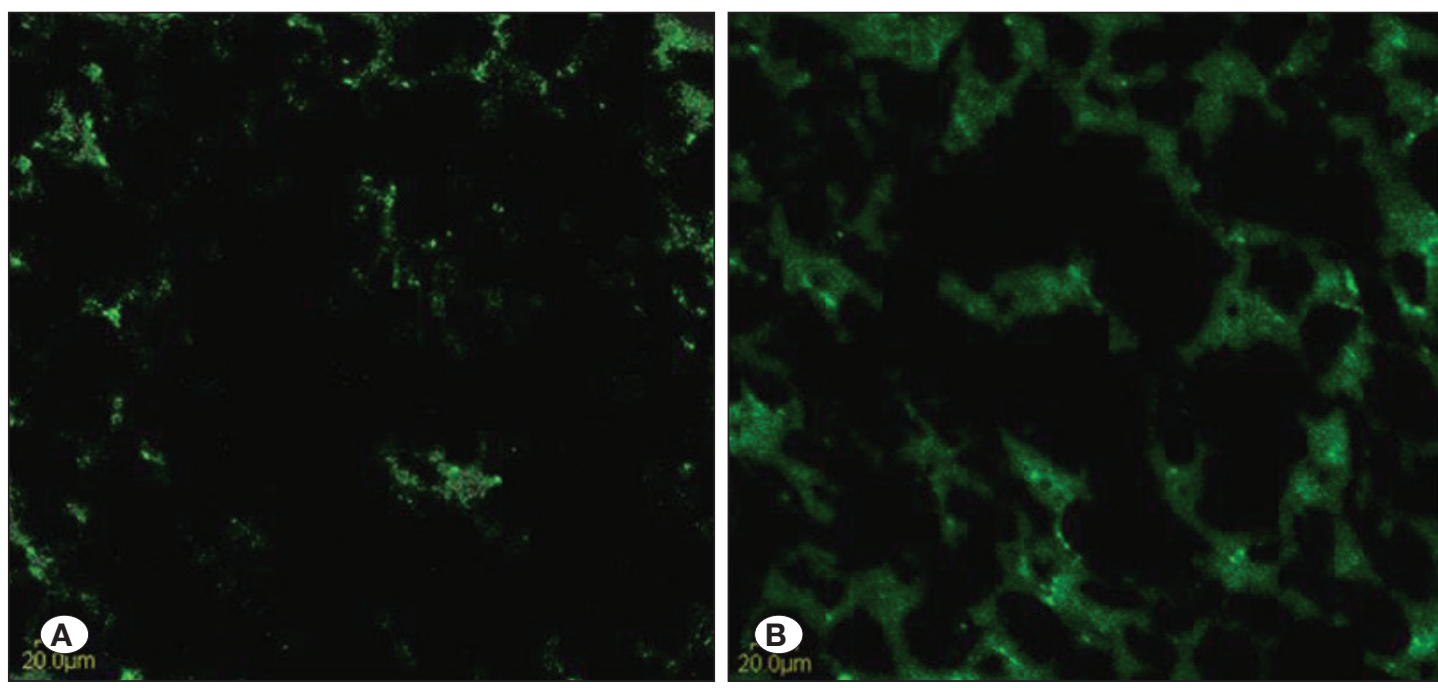

Figure 3: D-serine immunohistochemical staining. A) The control group and B) the intractable epilepsy group. D-serine positive cells can be observed in both groups (green fluorescence), and the expression level in the intractable epilepsy group was higher than that in the control group.

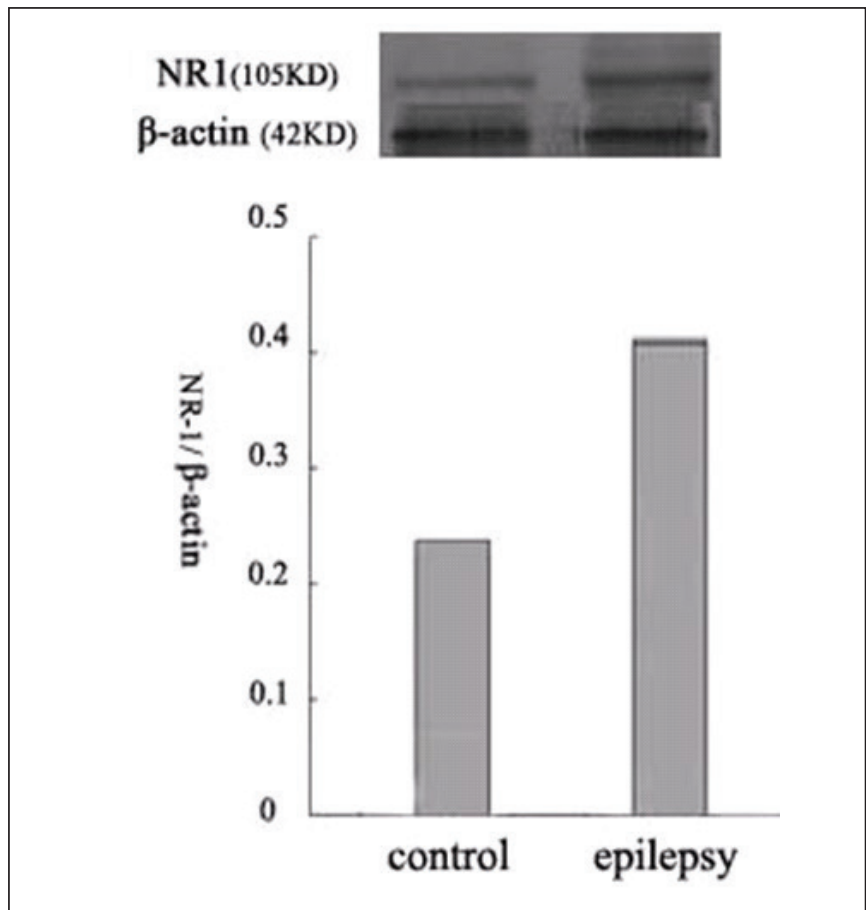

Figure 4: Western blot analysis of NMDA receptor 1 expression in the temporal lobes of the intractable epilepsy group and the control group. The absorbance value for the intractable epilepsy group was $0.4175 \pm 0.2321$, compared with $0.2402 \pm 0.1458$ for the control group $(p<0.05)$.

\section{Western Blot Analysis}

The western blot analysis revealed that the NMDA receptor 1 protein was detected as a band at $105 \mathrm{kDa}$. The NMDA receptor 1 to $\beta$-actin absorbance ratio was calculated for both groups. The absorbance ratio for the intractable epileptic tissue was $0.4175 \pm 0.2321$, which was significantly higher than the value of $0.2402 \pm 0.1458$ for the control group (Figure $4 ; p<0.05)$.

\section{DISCUSSION}

Epilepsy is a neurological disorder characterized by the transient disturbance of cerebral function due to recurrent, abnormal, neuronal discharges. Although the exact etiology and pathogenesis of epilepsy remain unclear, recent studies have suggested that an imbalance between glycine and gamma-aminobutyric acid may play a role in the pathogenesis of intractable epilepsy $(1,24)$.

The NMDA receptor is a glutamate receptor widely distributed throughout the central nervous system. Previous studies have suggested that the NMDA receptor may play significant roles in neuroplasticity and synapse transmission. The upregulation of the NMDA receptor has been associated with neuronal death and epilepsy development $(13,14)$. Although the structure of the NMDA receptor remains unclear, the NMDA receptor has three isoforms, NMDA receptors 1,2 , and 3 , and the subunits have been extensively studied $(4-6,19)$. The activation of the NMDA receptor has been associated with neurotoxicity. Several studies have suggested that NMDA receptor upregulation may play a role in the pathogenesis of epilepsy and that changes in the NMDA receptor subunits may occur following seizure episodes (28). One study found that the expression of NMDA receptor subunit did not differ in the cerebral cortex and hippocampus between an epilepsy rat model and a control rat after one seizure attack (2). However, in rats with recurrent seizure attacks, the ratios of NMDA receptor 1 and NMDA receptor 2 to NMDA receptor 2B were down-regulated in the cerebral cortex compared with those in controls (2). In our study, western blot analysis revealed that the expression levels of NMDA receptor 1 were significantly increased in the temporal lobes of patients with intractable epilepsy compared with control patients. Therefore, NMDA receptor upregulation may be associated with susceptibility to and the pathogenesis of intractable epilepsy. Our NMDA receptor 1 expression findings were different from those reported in previous animal studies, suggesting that animal models may not adequately represent human epilepsy. Most previous studies have used animal models to investigate the expression of NMDA receptors. However, animal studies are 
limited and may not represent the physiological conditions in human beings. In the present study, we used brain tissues collected from patients with intractable epilepsy; therefore, our results provide a more realistic representation of the pathogenesis of the human disease.

D-serine is a neurotransmitter widely distributed throughout the central nervous system. It is synthesized from L-serine by serine racemase (SR) in the brain $(20,22)$. Moreover, D-serine serves as a more potent agonist at the glycine site of the NMDA-type glutamate receptor $(8,23)$ than glycine. Therefore, D-serine likely acts as a signaling molecule in the brain and may participate in the pathogenesis of a variety of diseases. The activation of the glycine receptor results in the release of D-serine and glycine by astrocytes $(12,16,18)$.

Recently, D-serine and the NMDA receptor have become the focus of intense public attention. Previous studies have suggested that schizophrenia may be associated with the downregulation of NMDA receptors. Further investigation has revealed that $\mathrm{D}$-serine levels in the cerebrospinal fluid were significantly lower in patients with schizophrenia than control patients (9). Currently, D-serine is being investigated as an antipsychotic agent for the treatment of schizophrenia in clinical trials. SR-KO mice exhibited seizure alleviation, and a pentylenetetrazole-induced increase in glutamate levels was completely prevented in SR-KO mice (7). In a study of status epilepticus, Kang found that D-serine and SR in astrocytes may play roles in neuronal hyperexcitability via the cooperative activation of NMDA receptors (21). SR may be associated with the migration and differentiation of immature astrocytes, which is associated with reactive astrogliosis (21). Wang examined epileptic rats and patients with temporal lobe epilepsy and found that D-serine is involved in the development of epilepsy, partially through extracellular signal-regulated kinase signaling (11). These studies revealed that D-serine and NMDA receptor 1 may represent potential targets for the treatment of epileptic seizures.

\section{CONCLUSION}

In summary, we investigated the expressions of D-serine and NMDA receptor 1 in the temporal lobes of 20 patients with intractable epilepsy by immunofluorescence staining and western blot analysis. We found that D-serine expression was significantly increased in patients with intractable epilepsy compared with control patients. Based on our observations, we propose that overexpression of D-serine in neurons and glial cells may participate in the activation of NMDA and the development of neurotoxicity. In addition, the results of our study suggested that D-serine may play a key role in the pathogenesis of intractable epilepsy. Therefore, the D-serine signaling pathway may represent a potential neurochemical target for the future treatment of epilepsy.

\section{- REFERENCES}

1. Atmaca MM, Tuzun E, Erdag E, Bebek N, Baykan B, Gurses C: Investigation of anti-neuronal antibodies in status epilepticus of unknown etiology: A prospective study. Acta Neurol Belg 117(4):841-848, 2017
2. Bo $T$, Jiang $\mathrm{Y}, \mathrm{Cao} \mathrm{H}$, Wang J, Wu X: Long-term effects of seizures in neonatal rats on spatial learning ability and $\mathrm{N}$-methyl-D-aspartate receptor expression in the brain. Brain Res Dev Brain Res 152(2):137-142, 2004

3. Brodie MJ, Kwan P: Staged approach to epilepsy management. Neurology 58(8 Suppl 5):S2-8, 2002

4. Cull-Candy S, Brickley S, Farrant M: NMDA receptor subunits: Diversity, development and disease. Curr Opin Neurobiol 11(3):327-335, 2001

5. Cull-Candy SG, Leszkiewicz DN: Role of distinct NMDA receptor subtypes at central synapses. Sci STKE 2004(225):re16, 2004

6. Fang $X Q, X u$ J, Feng S, Groveman BR, Lin SX, Yu XM: The NMDA receptor NR1 subunit is critically involved in the regulation of NMDA receptor activity by $\mathrm{C}$-terminal Src kinase (Csk). Neurochem Res 36(2):319-326, 2011

7. Harai T, Inoue R, Fujita Y, Tanaka A, Horio M, Hashimoto K, Hongou K, Miyawaki T, Mori H: Decreased susceptibility to seizures induced by pentylenetetrazole in serine racemase knockout mice. Epilepsy Research 102(3):180-187, 2012

8. Hashimoto A, Nishikawa T, Oka T, Takahashi K: Endogenous $\mathrm{D}$-serine in rat brain: $\mathrm{N}$-methyl-D-aspartate receptor-related distribution and aging. J Neurochem 60(2):783-786, 1993

9. Helboe L, Egebjerg J, Moller M, Thomsen C: Distribution and pharmacology of alanine-serine-cysteine transporter 1 (asc-1) in rodent brain. Eur J Neurosci 18(8):2227-2238, 2003

10. Kalia LV, Kalia SK, Salter MW: NMDA receptors in clinical neurology: Excitatory times ahead. The Lancet Neurology $7(8): 742-755,2008$

11. Ma T, Wu Y, Chen B, Zhang W, Jin L, Shen C, Wang Y, Liu Y: D-Serine contributes to seizure development via extracellular ERK signaling. Frontiers in Neuroscience 13:254, 2019

12. Martineau M, Galli T, Baux G, Mothet JP: Confocal imaging and tracking of the exocytotic routes for D-serine-mediated gliotransmission. Glia 56(12):1271-1284, 2008

13. Masu M, Nakajima $Y$, Moriyoshi K, Ishii T, Akazawa C, Nakanashi S: Molecular characterization of NMDA and metabotropic glutamate receptors. Ann NY Acad Sci 707:153164, 1993

14. Mcllhinney RA, Philipps E, Le Bourdelles B, Grimwood S, Wafford K, Sandhu S, Whiting P: Assembly of N-methyl-Daspartate (NMDA) receptors. Biochem Soc Trans 31(Pt 4):865868, 2003

15. Mothet JP, Parent AT, Wolosker H, Brady RO Jr, Linden DJ, Ferris CD, Rogawski MA, Snyder SH: d-Serine is an endogenous ligand for the glycine site of the N-methyl-daspartate receptor. Proc Natl Acad Sci U S A 97(9):4926-4931, 2000

16. Mothet JP, Pollegioni L, Ouanounou G, Martineau M, Fossier P, Baux G: Glutamate receptor activation triggers a calcium-dependent and SNARE protein-dependent release of the gliotransmitter D-serine. Proc Natl Acad Sci U S A 102(15):5606-5611, 2005

17. Niimura M, Moussa R, Bissoon N, Ikeda-Douglas C, Milgram NW, Gurd JW: Changes in phosphorylation of the NMDA receptor in the rat hippocampus induced by status epilepticus. Journal of Neurochemistry 92(6):1377-1385, 2005 
18. Oliet SH, Mothet JP: Regulation of N-methyl-D-aspartate receptors by astrocytic D-serine. Neuroscience 158(1):275283, 2009

19. Rauner C, Köhr G: Triheteromeric NR1/NR2A/NR2B receptors constitute the major $\mathrm{N}$-methyl-D-aspartate receptor population in adult hippocampal synapses. J Biol Chem 286(9):7558-7566, 2011

20. Ribeiro CS, Reis M, Panizzutti R: Glial transport of the neuromodulator D-serine. Brain Res 929(2):202-209, 2002

21. Ryu HJ, Kim JE, Yeo SI, Kim DS, Kwon OS, Choi SY, Kang TC:Potential roles of $\mathrm{D}$-serine and serine racemase in experimental temporal lobe epilepsy. Journal of Neuroscience Research 88(11):2469-2482,2010

22. Schell MJ: The N-methyl D-aspartate receptor glycine site and D-serine metabolism: An evolutionary perspective. Philos Trans R Soc Lond B Biol Sci 359(1446 ):943-964, 2004

23. Schell MJ, Brady RO Jr, Molliver ME, Snyder SH: D-serine as a neuromodulator: Regional and developmental localizations in rat brain glia resemble NMDA receptors. J Neurosci 17(5):1604-1615, 1997
24. Spatola M, Dalmau J: Seizures and risk of epilepsy in autoimmune and other inflammatory encephalitis. Curr Opin Neurol 30(3):345-353, 2017

25. Sutula T, Cascino G, Cavazos J, Parada I, Ramirez L: Mossy fiber synaptic reorganization in the epileptic human temporal lobe. Ann Neurol 26(3):321-330,1989

26. Sutula T, Koch J, Golarai G: NMDA receptor dependence of kindling and mossy fiber sprouting: Evidence that the NMDA receptor regulates patterning of hippocampal circuits in the adult brain. J Neurosci 16(22):7398-7406, 1996

27. Walker M: Neuroprotection in epilepsy. Epilepsia 48(s8):66-68, 2007

28. Yang J,Woodhall GL, Jones RS: Tonic facilitation of glutamate release by presynaptic NR2B-containing NMDA receptors is increased in the entorhinal cortex of chronically epileptic rats. Journal of Neuroscience 26(2):406-410, 2006 